\title{
Perbaikan Pengkabelan Trafo Arus pada REF (Restricted Earth Fault) dan SBEF (Standby Earth Fault) untuk Meningkatkan Selektivitas Kerja Relay
}

\author{
Agus Siswanto $^{\# 1}$, Petra Aprilia Pandiksa Santi ${ }^{* 2}$, Taufik Susanto ${ }^{\# 3}$

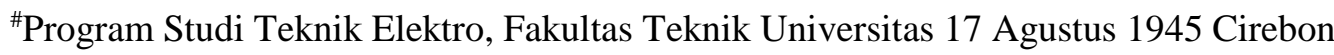 \\ Jl. Perjuangan, No. 17 Kota Cirebon, Jawa Barat, Indonesia \\ 1asiswanto. untagcrbegmail.com \\ ${ }^{2}$ petraaprilia95@gmail.com \\ *Staff Ahli Kementrian Energi dan Sumber daya Mineral, \\ Badan Penelitian dan Pengembangan Energi dan Sumber daya mineral, \\ Pusat Penelitian dan Pengembangan Geologi Kelautan (P3GL) Cirebon \\ J1. Perjuangan, No. 17 Kota Cirebon, Jawa Barat, Indonesia \\ 3taufiksusanto94@gmail.com
}

Abstrak-

Transformator merupakan unsur utama dan merupakan mata rantai terpenting dalam penyaluran dan distribusi tenaga listrik.Sehingga diperlukan sistem proteksi yang selektif, andal, sensitif, dan cepat untuk menjaga keandalan trafo.Salah satu komponen proteksi trafo adalah CT (trafo arus) yang berfungsi sebagai pembaca arus proteksi relay, apabila terjadi gangguan maka relay proteksi mendeteksi adanya keabnormalan sehingga memberikan sinyal trip pada PMT (pemutus Tenaga) untuk memutus rangkaian listrik.Relay pada sistem proteksi trafo memiliki lokasi pengamanan yang berbeda. Di PT. PLN (Persero) UPT Cirebon, terjadi gangguan pada bay trafo yang mengakibatkan relay bekerja. Namun kerja relay ini tidak sesuai dengan lokasi gangguan yang terjadi. Setelah diinvestigasi didapatkan bahwa CT pada bay trafo memiliki desain peletakan yang kurang tepat sehingga mengakibatkan salah kerja relay (less selective). Untuk memperbaiki kesalahan tersebut, maka dilakukan perubahan pengkabelan $\mathrm{CT}$ pada trafo produksi lama.Perubahan pengkabelan CT ini disesuaikan dengan ketentuan SPLN T5.003-2010 Tentang Standar Pola Proteksi Transformator Tenaga sehingga apabila terjadi gangguan relay bekerja sesuai dengan lokasi proteksinya. Hasil yang diperoleh, terbukti pada saat terjadi gangguan setelah dilakukan perubahan pengkabelan relay bekerja sesusai dengan fungsinya, sehingga prinsip sistem proteksi terpenuhi, yaitu selektif, andal, sensitif dan cepat.
Kata kunci: Sistem proteksi, Malfungsi relay, Desain Pengkabelan, Trafo Arus, SBEF (Standby Earth Fault)

Abstract-The transformer is the main element and is the most important link in the distribution and distribution of electricity. So we need a selective, reliable, sensitive, and fast protection sistem to maintain the reliability of the transformer. One component of the transformer protection is the CT (Current Transformer) which functions as a relay protection current reader if a disturbance occurs then the protection relay detects an abnormality so that it gives a trip signal to the PMT (power breakers) to disconnect the electrical circuit. Relay on the transformer protection systemhas a different secure location. At PT. PLN (Persero) UPT Cirebon, there was a disruption in the transformer bay which resulted in the relay working. However, the relay's work does not match the location of the disturbance. After investigation, it was found that CT on the transformer bay had an inaccurate laying design resulting in less selective relay work. To correct this error, changes were made to the $C T$ cabling in the old production transformer. Changes to the CT cabling are adjusted to the provisions of SPLN T5.003-2010 About the Standards of the Power Transformer Protection Pattern so that in the event of a relay interference it works according to the location of its protection. The results obtained are proven when interference occurs after a change in cabling relay works in accordance with its function, so that the protection systemprinciple is fulfilled, namely selective, reliable, sensitive, and fast.

Keywords: Protection system, Relay malfunction, Pengkabelan Design, Current Transformer, SBEF (Standby Earth Fault) 


\section{Pendahuluan}

Sistem tenaga listrik bersumber dari pembagkit yang terdri dari PLTU (pembangkit Listrik Tenaga Uap), PLTA (pembangkit Listrik Tenaga air) dan PLTB (Pembangkit Listrik Tenaga Bayu), [1-3] bertempat jauh dari pusat-pusat beban sehingga diperlukan jaringan transmisi dan distribusi untuk menghubungkan. Terdapat peralatan lain untuk mendukung menyalurkan daya listrik tersebut yaitu transformator yang merupakan alat yang berfungsi untuk menaikan dan menurunkan tegangan.

Transformator merupakanbagian unsur utama mata rantai sistem penyaluran distribusi tenaga listrik. Sistem penyaluran listrik sangat bergantung pada keandalan kerja transformator tenaga.Sistem proteksi merupakan perlindungan suatu peralatan dari gangguan.Tujuan utama proteksi tenaga listrik yaitu untuk mencegah terjadi gangguan secara total atau memadamkan gangguan yang telah terjadi dan melokalisir.Untuk menjaga keandalan transformator tenaga perlu sistem proteksi yang selektif, andal, sensitif, cepat, agar stabilitas sistem tetap terjaga $[4,5]$ sehingga dapat mengoptimalkan penyaluran daya dari pembangkit hingga beban agar tidak banyak kerugian disistem (loss in the system)[6]

Salah satu komponen proteksi pada transformator yaitu Trafo Arus atau Current Transformation (CT).[7-9]Untuk memproteksi transformator, terdapat beberapa CT untuk pembacaan arus proteksi pada relay, yaitu CT REF HV (Restricted Earth Faulthigh voltage), CT REF LV (Restricted Earth Faultlow voltage)dan CT SBEF. Peletakan CT untuk pembacaan arus proteksi harus sesuai untuk membatasi daerah yang diproteksi oleh suatu relay. Letak CT yang tidak sesuai menyebabkan relay bekerja tidak sesuai fungsinya[10-13]. Dampak dari relay yang tidak bekerja secara maksimal dapat meneybabkan kerusakan fatal pada system, karena pemadaman tidak dapat dilokalisir sesuai ganguan yang terjadi.

Di PT. PLN (Persero) UPT tersebut, pada trafo tenaga produksi lama memiliki desain peletakan CT yang kurang tepat, sehingga apabila terjadi gangguan atau ada ketidaknormalan pada besaran listrik menyebabkan salah kerja pada relay. Hal ini kerja relay menjadi kurang sesuai dengan area proteksinya. Untuk memperbaiki kesalahan tersebut, maka dilakukan perubahan posisi atau letak CT pada trafo produksi lama.

\section{Sistem Proteksi Tenaga Listrik}

Sistem proteksi untuk melindungi peralatan utama bila terjadi gangguan hubung singkat, dapat mengeliminir daerah yang terganggu sehingga gangguan tidak meluas. Bagain relay proteksi gardu induk terdiri dari:

- Relayproteksi Trafo Tenaga;

- Relayproteksi busbar atau kopel;

- Relayproteksi PMT (Pemutus Tenaga);

- Relayproteksi kapasitor dan reaktor.
- Relay arus lebih atau OCR (Over Current Relay)

- Relay Kesalahan Tanah GFR (Ground Fault Relay)

- Relay Tegangan Lebih OVR (Over Voltage Relay)

\subsection{PROTEKSI TRAFO TENAGA}

Peralatan proteksi trafo tenaga terdiri dari Trafo Tegangan (PT/CVT), RelayProteksi, , Pengkabelan,Trafo Arus (CT), PMT, Catu daya AC/DC yang saling terhubung dalam suatu rangkaian, sehingga terjadi saling keterkaitan satu sama lain..

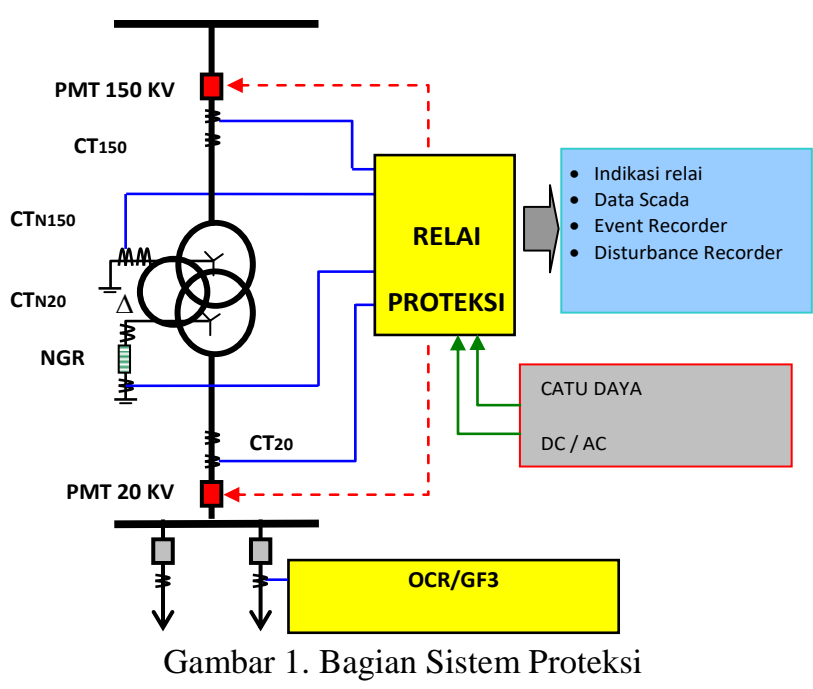

Jenis relay proteksi yang dibutuhkan dengan selektifitas tertentu tertera pada Tabel 1.

Tabel1. Kebutuhan Fungsi RelayProteksi Terhadap

\begin{tabular}{|c|l|c|c|c|}
\hline \multirow{2}{*}{ No } & Jenis gangguan & Utama & $\begin{array}{c}\text { Back } \\
\text { up }\end{array}$ & \multirow{2}{*}{ Akibat } \\
\cline { 3 - 4 } & $\begin{array}{l}\text { Hubung singkat } \\
\text { didaerah } \\
\text { pengaman trafo }\end{array}$ & $\begin{array}{c}\text { Diferensial } \\
\text { REF Bucholz } \\
\text { tangki tanah } \\
\text { tek. Lebih }\end{array}$ & $\begin{array}{l}\text { OCR } \\
\text { dan } \\
\text { GFR }\end{array}$ & $\begin{array}{c}\text { Kerusakan pada } \\
\text { isolasi kumparan } \\
\text { atau inti tangki } \\
\text { meng-gembung }\end{array}$ \\
\hline 2 & $\begin{array}{l}\text { Hubung singkat } \\
\text { diluar daerah } \\
\text { pengaman trafo }\end{array}$ & $\begin{array}{c}\text { OCR }, \\
\text { GFR .dan } \\
\text { SBEF }\end{array}$ & $\begin{array}{c}\text { OCR } \\
\text { dan } \\
\text { GFR }\end{array}$ & $\begin{array}{c}\text { Kerusakan pada } \\
\text { isolasi atau } \\
\text { kumparan atua } \\
\text { NGR }\end{array}$ \\
\hline 3 & Beban lebih & Rele suhu & OCR & Kerusakan isolasi \\
\hline 4 & $\begin{array}{l}\text { Gangguan } \\
\text { sistem pending }\end{array}$ & $\begin{array}{c}\text { Rele suhu } \\
\text { Kerusakan isolasi }\end{array}$ \\
\hline 5 & $\begin{array}{l}\text { Gangguan pada } \\
\text { OLTC }\end{array}$ & $\begin{array}{c}\text { Jansen Tek. } \\
\text { Lebih }\end{array}$ & & Kerusakan OLTC \\
\hline 6 & Tegangan lebih & OVR & & Kerusakan isolasi \\
\hline
\end{tabular}

\subsection{TRAFO ARUS}

Trafo Arus yang sering disebut (Current Transformator-CT).peralatan tersebutberfungsi untuk melakukan pengukuran besaran arus pada intalasi tenaga listrik disisi primer (TT ,TET, dan TM) berskala besar. Dalammelakukan transformasi dari besaran arus yang besar dari jaringan system transmisi atau distribusi menjadi besaran arus yang kecil secara akurat dan teliti untuk keperluan proteksi dan pengukuran. 
Fungsi dari trafo arus adalah:

a) Trafo dapat mengubah besaran arus pada sistem tenaga listrik dari besaran primer menjadi besaran sekunder untuk keperluan pengukuran sistem metering dan proteksi

b) Trafo berfungsi mengisolasi rangkaian sekunder terhadap rangkaian primer, sebagai pengamanan terhadap manusia (operator )yang melakukan pengukuran.

c) Trafo dapat menjadi standarisasi besaran sekunder, untuk arus nominal 1 Amp dan 5 Amp

\subsection{Restricted Earth Fault (REF)}

REF merupakan relay yang memiliki fungsi dalam mengamankan transformator bila ada gangguan satu fasa ke tanah di dekat titik netral transformator yang tidak dirasakan oleh relay differensial[10]. Prinsip kerja relayREF mirip sepertirelaydifferensial, yaitu membandingkan besar arus sekunder kedua trafo arus yang digunakan, tetapi batasan daerah kerja hanya antara CT titik netral denganCT fasa. REF digunakan dalam memproteksi gangguan 1-fasa ketanah. Relay tidak akan bekerja ketika tidak terjadi gangguan (keadaan normal) atau gangguan di luar daerah pengaman, maka ke dua arus sekunder tersebut di atas besarnya sama, sehingga tidak ada arus mengalir pada relay.Relay akan bekerja ketika terjadi gangguan di daerah pengamanan, sehingga kedua arus sekunder trafo arus besar tidak sama oleh karena itu, ada arus yang mengalir pada relay.

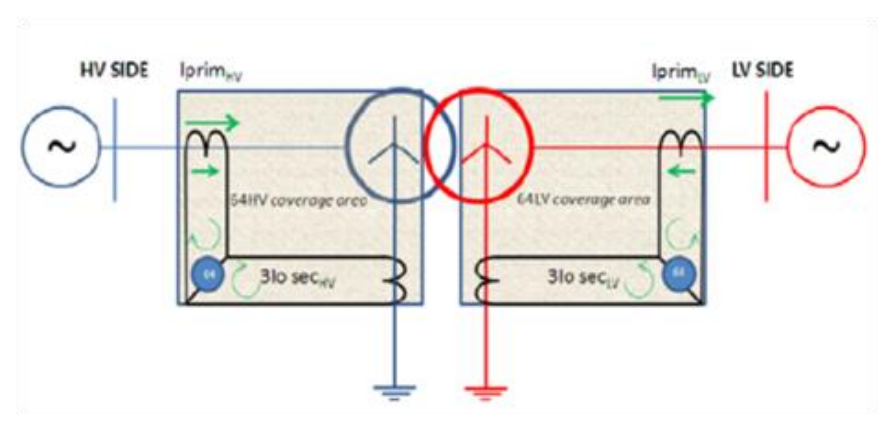

Gambar 2. Skema Relay REF

\subsection{Stand By Earth Fault Relay (SBEF)}

Karakter darirelayjenis ini berfungsi untuk mengamankan NGR (Neutral Grounding Resistant) dari kerusakan akibat panas. Ketika arus hubung singkat atau arus urutan nol yang mengalir ke titik netral transformator secara terus menerus (continue) maka akan terjadi panas[14]. Prinsip kerja relaytersebutsama dengan relaygangguan ke tanah (GFR) dan dipasang hanya untuk pentanahan yang sifatnyatidak langsung.Karakteristik waktu kerja SBEF adalah kurva landai (long time inverse) seperti pada gambar 3 dibawah ini.

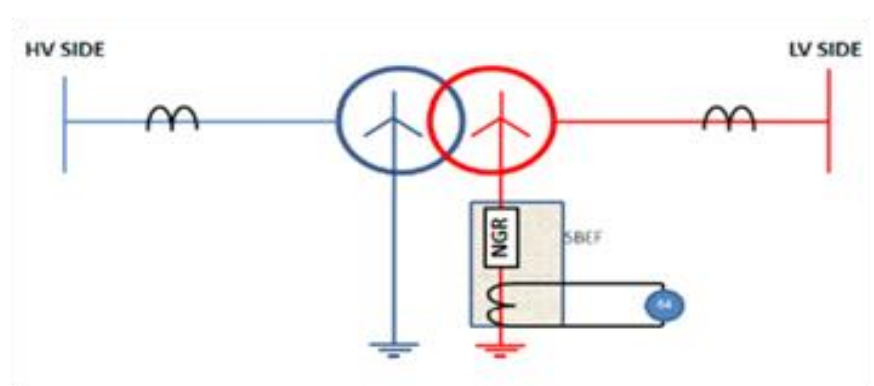

Gambar 3. Skema Pengkabelan SBEF

\subsection{Lokasi Penempatan CT}

Untuk menentukan lokasi CT dapat mempengaruhi luas pengamanan (coverage area) dari relayproteksi itu sendiri. Konfigurasi CT eksisting pada aplikasi REF yangterpasang disistem P3B Jawa Bali yaitu:

1. CT Netral terpasang antara titik netral transformator dengan NGR.

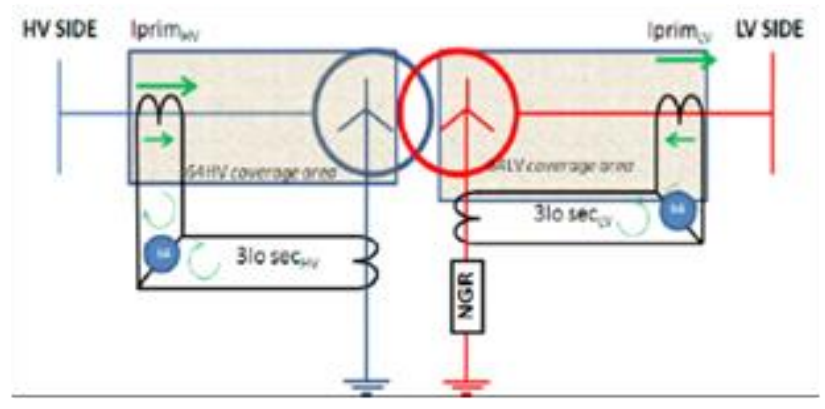

Gambar 4. Konfigurasi CT Netral antara Titik Netral dengan NGR

PT PLN (Persero) P3B Jawa Bali merekomendasikan konfigurasi CT Netral antara Titik Netral dengan NGR.Pada konfigurasi tersebut REF berfungsi untuk melindungi belitan ke titik netral transformator dan tidak melindungi NGR transformator yang terpasang dalam sistem.

2. CT Netral terinstal antara NGR dan titik pentanahan dalam sistem. 


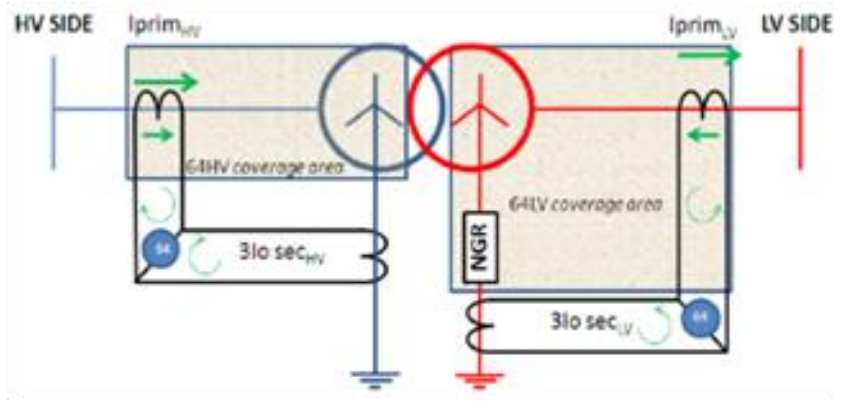

Gambar 5.Bentuk CT Netral antara Titik Pentanahan terpasang dengan NGR

\section{Pembahasan dan Analisis}

\subsection{Desain Pengkabelan CT pada Trafo Produksi Lama}

Berikut merupakan Pengkabelan CT pada bay trafo eksisting di PT.PLN (Persero) UPT tersebut:

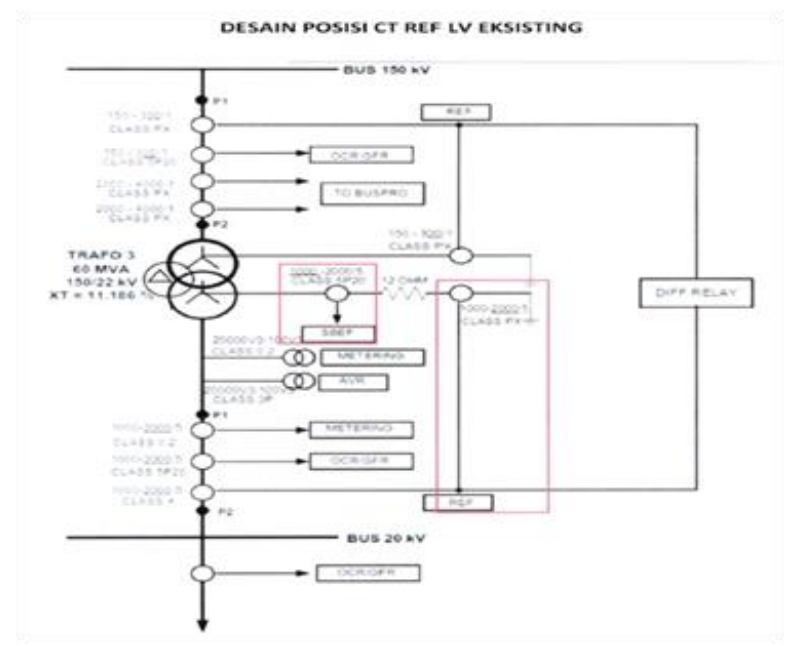

Gambar 6. Desain Pengkabelan Trafo Lama

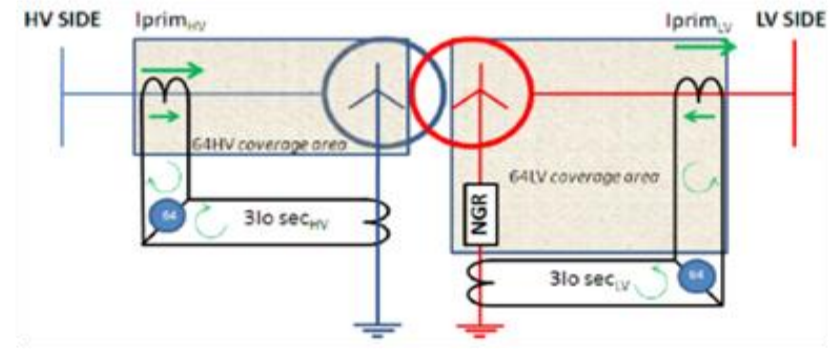

Gambar 7. Desain Pengkabelan REF Trafo Lama

Pada trafo produksi lama posisi CT REF sisi (Low Voltage) LV dipasang setelah NGR, yaitu diantara titik pentanahan dan NGR. Sedangkan posisi SBEF berada diantara titik netral trafo dengan NGR.Sehingga setiap kali ada gangguan pada NGR, relayyang bekerja adalah REF LV bukan SBEF.Dalam hal ini fungsi REF menjadi tidak sesuai dengan area proteksi, karena REF tidak hanya menjadi proteksi untuk gangguan internal trafo, tetapi menjadi proteksi NGR juga. Seharus apabila terjadi gangguan pada NGR relay yang bekerja adalah relay SBEF. Karena sesuai dengan fungsinya relay SBEF merupakan relay yang berfungsi untuk melindungi NGR dari panas baik akibat hubung singkat maupun arus urutan nol mengalir ke titik netral transformator secara terus menerus.

\subsection{Keandalan Sistem Proteksi Trafo Produksi Lama}

Berikut merupakan merekam data (record data) gangguan pada PT. PLN (Persero) UPT tersebut :

Tabel 2. Data Gangguan Bay Trafo

\begin{tabular}{|c|c|c|c|c|}
\hline $\mathrm{No}$ & Tanggal & Lokasi & Penyebab & Relay Kerja \\
\hline 1 & $\begin{array}{c}24.09 .2 \\
017\end{array}$ & $\begin{array}{c}\text { GI } \\
\text { Pameungp } \\
\text { euk } \\
\text { TRF \#3 }\end{array}$ & $\begin{array}{c}\text { Isolator } \\
\text { Flash pada } \\
\text { NGR }\end{array}$ & $\begin{array}{l}\text { Differential, } \\
\text { REF } 20 \mathrm{kV}\end{array}$ \\
\hline 2 & $\begin{array}{c}27 \\
\text { Maret } \\
2018\end{array}$ & $\begin{array}{c}\text { GI } \\
\text { Indramayu } \\
\text { TRF \#3 }\end{array}$ & $\begin{array}{c}\text { Short Kabel } \\
\text { NGR ke } \\
\text { Body }\end{array}$ & SBEF \\
\hline
\end{tabular}

Pada tanggal 24 September 2017 terjadi gangguan pada Trafo 3 GI Pameungpeuk yang disebabkan oleh polutan penggaraman karena lingkungan sekitar GI adalah pantai, sehinga menyebabkan isolator flash pada NGR. Berikut merupakan gambar isolator flash akibat gangguan tersebut :
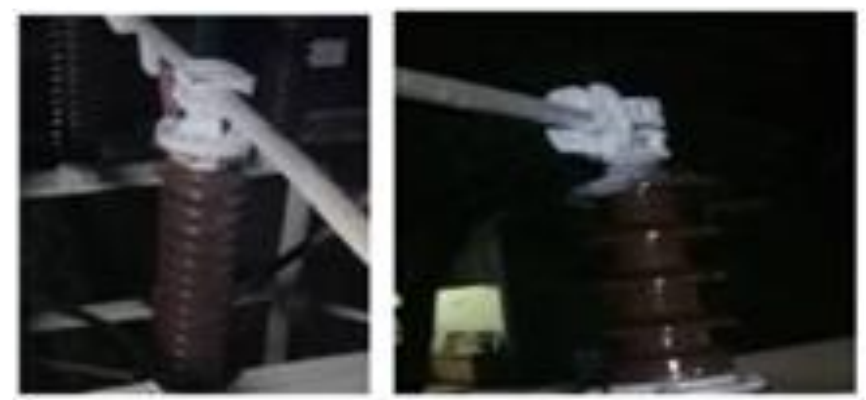

Gambar 8. Isolator Flash pada NGR

Seharusnya berdasarkan area proteksi REF dan Differential Relay gangguan ini bukan merupakan area proteksinya. Gangguan yang terjadi merupakan gangguan eksternal trafo (NGR), sehingga yang seharusnya bekerja adalah relay SBEF. Dengan desain pengkabelan lama seperti gambar 3.1 dan gambar 3.2 menyebabkan relay REF salah kerja. Ketika terjadi gangguan tersebut maka relay akan bekerja dengan skema ditunjukkan pada gambar 3.3 berikut. 


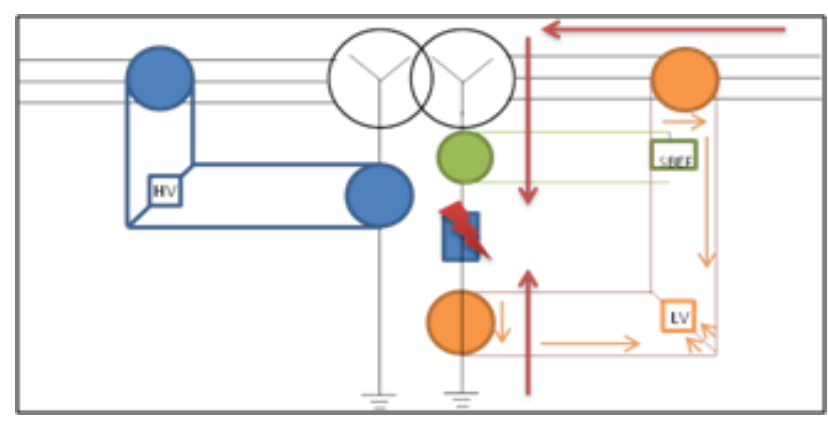

Gambar 9. Skema Kerja REF LV Desain Baru

Pada Gambar 9 tersebut dijelaskan bahwa relay REF LV akan bekerja karena memiliki 2 input arus dengan arah yang sama. Arah yang sama tersebut akan menjadi operasi saling menambahkan sehingga nilai input relay tidak sama dengan 'nol' dan relay akan bekerja. Sehingga dapat dikatakan sistem proteksi trafo produksi lama dinilai kurang handal.

Setelah terjadinya gangguan pada tahun 2017 tersebut, yang mana menyebabkan relay salah kerja maka dilakukan pengkajian ulang mengenai desain pengkabelan CT pada REF dan SBEF pada trafo produksi lama. Operasi kerja relay REF $20 \mathrm{kV}$ dengan desain lama tersebut tidak sesuai dengan filosofi, untuk menghindari kejadian serupa maka pada akhir tahun 2017 semua trafo dengan desain lama dilakukan perubahan pengkabelan CT REF dan SBEF, hal ini agar relay bekerja sesuai dengan fungsi proteksinya. Perubahan pengkabelan CT ini disesuaikan dengan ketentuan SPLN T5.003-2010 Tentang Standar Pola Proteksi Transformator Tenaga. Diharapkan jika pengkabelan telah mengikuti desain yang sesuai dengan ketentuan tersebut maka REF tidak akan bekerja pada saat terjadi gangguan pada NGR. Berikut merupakan desain pengkabelan CT REF dan SBEF setelah dilakukan perubahan :

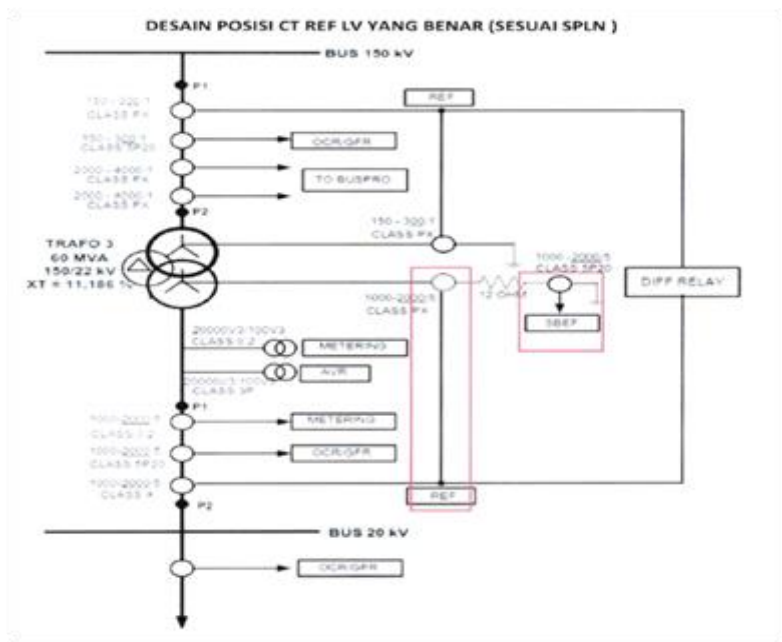

Gambar 10. Desain Posisi CT REV LV sesuai PLN
Skema kerja REF dapat digambarkan pada Gambar 11 dibawah ini:

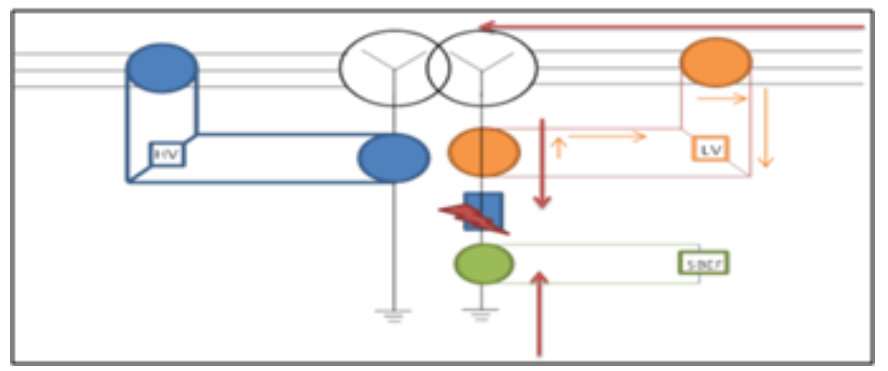

Gambar 11. Skema Kerja REF LV Desain Baru

Berdasarkan skema tersebut maka apabila terjadi gangguan pada NGR maka yang akan kerja adalah relay SBEF.

Setelah dilakukan perubahan pengkabelan pada CT REF dan SBEF, terjadi gangguan lagi pada tanggal 27 Maret 2018 di GI Indramayu Trafo \#3, yang mana gangguan ini disebabkan karena adanya kabel yang menempel di tubuhNGR, maka relay yang bekerja hanya relay SBEF 20kV. Hal ini sudah sesuai dengan area proteksi SBEF.

SBEF akan bekerja untuk mengamankan NGR dari panas atau arus berlebih. Gangguan yang terjadi pada NGR terdapat arus sebesar 1,35A. SBEF memiliki setting sebagai berikut:

$$
\begin{aligned}
& \text { I nominal Relay }(\mathrm{InR})=5 \mathrm{~A} \\
& \text { Iset SBEF }=\frac{0.2 \times \mathrm{In} \text { NGR }}{\mathrm{CT} \mathrm{NGR}} \\
& \text { Iset SBEF }=\frac{0.2 \times 750}{200}=0,75 \mathrm{~A}
\end{aligned}
$$

SBEF akan bekerja apabila CT mendeteksi arus lebih dari Isetting. Isetting pada SBEF trafo \#3 Indramayu lebih rendah dari arus gangguan yang terjadi, sehingga dapat dipastikan SBEF bekerja untuk mengamankan NGR.

Relay dalam sistem proteksi harus dapat bekerja dengan andal dan selektif sesuai dengan daerah kerja yang diamankan. Relay yang selektif akan mempermudah dalam pelaksanaan investigasi gangguan. Karena relay sudah didesain dengan area kerja masing-masing, jika relay tersebut bekerja maka akan dengan cepat teridentifikasi letak gangguan. Namun apabila relay salah kerja atau tidak selektif mengamankan daerah yang bukan area pengamanannya, akan mempersulit investigasi dan membutuhkan waktu investigasi lebih lama .

\section{Kesimpulan}

1. REF dan SBEF merupakan relay proteksi utama pada transformator. REF memproteksi didalam daerah pengamanan trafo diluar area proteksi relay differensial danSBEF memproteksi diluar daerah pengamanan trafo. 
2. Skema proteksi trafo pada trafo produksi lama di PT.PLN (Persero) UPT tersebut yaitu REF menggunakan 3 CT yang diletakkan di sisi HV, LV, dan setelah NGR, sedangkan SBEF menggunakan 1 CT yang diletakkan di NGR atau sebelum NGR. sehingga mengakibatkan salah kerja pada relay.

3. Berdasarkan desain eksisting pengkabelanCTREF dan SBEF pada trafo produksi lama di PT.PLN (Persero) UPT Cirebon, sistem proteksi relay tersebut kurang handal karena relay bekerja tidak selektif sesuai daerah pengamannannya.

4. Perlu dilakukan perbaikan pengkabelan CT REF dan SBEF agar REF dan SBEF bekerja sesuai dengan fungsinya.

\section{UCAPANTERIMAKASIH}

Terima kasih pada Fakultas Teknik Universitas 17 Agustus 1945 Cirebon yang telah memberikan support dan pendanaan dalam publikasi.

\section{REFERENSI}

[1] Siswanto, A., Steady State Stability Limit Assessment when Wind Turbine Penetrated to the Systems using REI Approach. Vol. 1. 2019. 53-57.

[2] Agus Siswanto, S.a.E.S., The Voltage Stability of Distribution Sistem using the Distribution Generation Biomass Power Plant. Proceeding of International Conference on Green Technology, 2014. ISSN:23553456.

[3] Siswanto, A., et al., Stability improvement of wind turbine penetrated using power sistem stabilizer (PSS) on South Sulawesi transmission system. AIP Conference Proceedings, 2018. 1941(1): p. 020036.

[4] Indar Chaerah Gunadin, Z.M.a.A.S., Transient stability improvement based on moment inertia index using extreme learning machine, ARPN Journal of Engineering and Applied Sciences,, 2019. VOL. 14, p. 2520-2528.

[5] Yuli Asmi Rahman, A.S., and irwan Mahmudi, Stability Issues in Presence Variable Distributed Generation Into Radial Distribution Network International Conference on Industrial Electrical and Electronics (ICIEE) 2018.

[6] Agus Siswanto, S., Analysis of Drop Voltage and Losses in 20 kVDistribution Sistem Using DistributionGeneration Biomass Plant. Engineering International Conference 2013 Proceeding, 2013.

[7] Jalil, K.J.A., et al. Performance of restricted earth fault protection scheme in the presence of current transformer remanence. in 2008 IEEE 2nd International Power and Energy Conference. 2008.

[8] Kasztenny, B., L. Sevov, and A. Jaques. New algorithm for lowimpedance restricted earth fault protection. in 2004 Eighth IEE International Conference on Developments in Power Sistem Protection. 2004.

[9] Tan, J., D. Tholomier, and H. Wei. A New Restricted Earth Fault Protection. in 2007 Canadian Conference on Electrical and Computer Engineering. 2007.

[10] Babu, K.N.D., et al. A case study on REF low impedance IED mal operation. in 2016 IEEE 6th International Conference on Power Systems (ICPS). 2016.

[11] Bertrand, P., B. Gotzig, and C. Vollet. Low impedance restricted earth fault protection. in 2001 Seventh International Conference on Developments in Power Sistem Protection (IEE). 2001.
[12] Davarpanah, M., M. Sanaye-Pasand, and R. Iravani, Performance Enhancement of the Transformer Restricted Earth Fault Relay. IEEE Transactions on Power Delivery, 2013. 28(1): p. 467-474.

[13] Ghanbari, T., H. Samet, and J. Ghafourifard, New approach to improve sensitivity of differential and restricted earth fault protections for industrial transformers. IET Generation, Transmission \& Distribution, 2016. 10(6): p. 1486-1494.

[14] Yin, L., Y. Xiao, and Z. Xu. A new principle based on Pearson correlation coefficient to avoid mal-operation of the restricted earth fault protection. in 22nd International Conference and Exhibition on Electricity Distribution (CIRED 2013). 2013. 